\title{
Application of UV-Spectroscopy and First Order Derivative Method for Determination of Tamsulosin Hydrochloride in Bulk and Tablets
}

\author{
S. B. Bari, A. R. Bakshi, P. S. Jain*, S. J. Surana
}

R. C. Patel Institute of Pharmaceutical Education and Research, Karwand Naka, Shirpur-425 405, Dhule (M.S.)

\begin{abstract}
Two simple, rapid, sensitive and accurate UV-Spectrophotometry and First order derivative methods have been developed for estimation of tamsulosin hydrochloride in bulk and tablets. Methanol: water $(2: 8)$ was used as a solvent. In UV spectrophotometric method absorbance of samples are recorded at $280 \mathrm{~nm}$. In first order derivative method the amplitude of trough was recorded at $298 \mathrm{~nm}$. Tamsulosin follows linearity in the concentration range of $10-90 \mu \mathrm{g} / \mathrm{ml}$. Assay results were in good agreement with label claim. These method were validated statistically and recovery studies.
\end{abstract}

Keywords: Tamsulosin hydrochloride (TMS); UVSpectrophotometry; First order derivative

\section{Introduction}

Tamsulosin hydrochloride is a sulphonamide derivative used in the treatment of Benign Prostate Hyperplasia (BPH), synonymously known as elders disease.TMS is official in Martindale-The Extra Pharmacopoeia and Merck Index [1,2]. TMS, (R)-5-[2-[[2-(2-ethoxyphenoxy)ethyl] amino]propyl]-2-methoxy-benzenesulfonamide, is a subtype selective $\mu_{1 \mathrm{~A}}$ and $\mu_{1 \mathrm{D}}$ adrenoceptor antagonist approved by the Food and Drug Administration (FDA), USA for treatment of BPH. It is a new type of highly selective $\alpha$-1-adrenergic receptor antagonist for treatment of $\mathrm{BPH}$. Compared to other $\alpha$-antagonists, tamsulosin hydrochloride has greater specificity for $\alpha-1$ receptors in the human prostate and does not affect receptors on blood vessels. Tamsulosin hydrochloride exists in two enantiomeric forms but only R-isomer is the pharmaceutically active component. Literature survey reveals the chiral separation by electrophoresis [3,4] and HPLC methods, coupled with ESI-MS-MS are reported for the estimation of tamsulosin hydrochloride with its impurities in bulk and pharmaceutical formulations [5] as well as in biological fluids [6-11]. According to our knowledge no method has been reported for TMS estimation by spectroscopic method. The present work deals with estimation of tamsulosin hydrochloride in bulk and pharmaceutical formulation by simple and derivative spectroscopy which is economical and intended for better reproducibility of product.

\section{Material and Methods}

\section{Chemicals}

All reagents used were of analytical grade.

\section{Instrument and conditions}

SHIMADZU AUX - 120 (Weighing Balance), UV Shimadzu 2450 (PC Series), UV-visible double beam spectrophotometer, Software UV Probe 2.21, Matched quartz cells $1 \mathrm{~cm}$, Wavelength range $190-900$ nm, Lamp: 50 w, Deuterium Lamp, Detector: Silicon Photodiode, Cell holder: $1 \mathrm{~mm}$ wide, $12 \mathrm{~mm}$ high Resolution: $1 \mathrm{~nm}$.

\begin{tabular}{|l|l|l|}
\hline Parameter & At $280 \mathrm{~nm}$ & At 298nm \\
\hline Linearity equation $(\mathrm{Y}=\mathrm{a}+\mathrm{bc})$ & $\mathrm{Y}=0.0107 \mathrm{X}+0.002$ & $0.0046 \mathrm{X}+0.0027$ \\
\hline Range $(\mu \mathrm{g} / \mathrm{mL})$ & $10.00-90.00$ & $10.00-90.00$ \\
\hline Correlation Coefficient $\left(\mathrm{r}^{2}\right)$ & 0.9993 & 0.9977 \\
\hline
\end{tabular}

Table 1: Linear regression data for the calibration curves.

\section{Results and Discussion}

Tamsulosin hydrochloride in methanol: water (20:80) solvent system showed absorbance maximum at $280 \mathrm{~nm}$. In 'first order

(a)

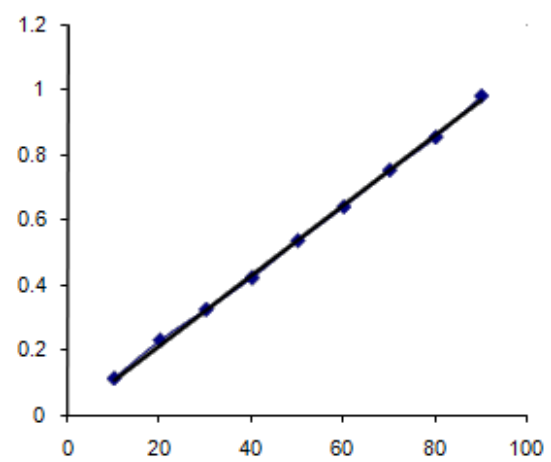

(b)

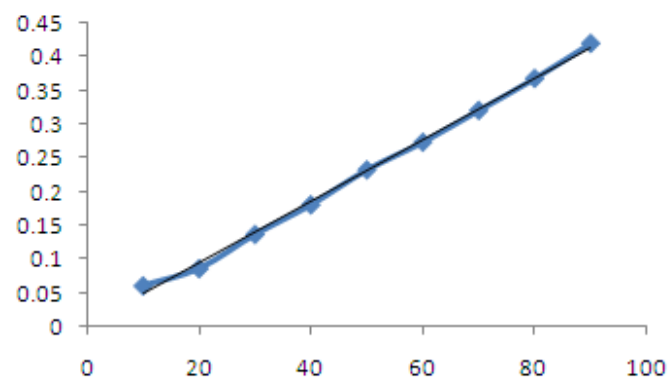

Figure 1: Calibration curve for TMS at $280 \mathrm{~nm}$ (a) $298 \mathrm{~nm}$ (b).

*Corresponding author: P. S. Jain, R. C. Patel Institute of Pharmaceutica Education and Research, Karwand Naka, Shirpur-425 405, Dhule (M.S.), Tel: +91 2563 255189; E-mail: pritash79@yahoo.com

Received August 30, 2010; Published April 08, 2011

Citation: Bari SB, Bakshi AR, Jain PS, Surana SJ (2011) Application of UVSpectroscopy and First Order Derivative Method for Determination of Tamsulosin Hydrochloride in Bulk and Tablets. Pharm Anal Acta 2:120. doi:10.4172/2153-2435.1000120

Copyright: ( 2011 Bari SB, et al. This is an open-access article distributed under the terms of the Creative Commons Attribution License, which permits unrestricted use, distribution, and reproduction in any medium, provided the original author and source are credited. 
Citation: Bari SB, Bakshi AR, Jain PS, Surana SJ (2011) Application of UV-Spectroscopy and First Order Derivative Method for Determination of Tamsulosin Hydrochloride in Bulk and Tablets. Pharm Anal Acta 2:120. doi:10.4172/2153-2435.1000120

Page 2 of 2

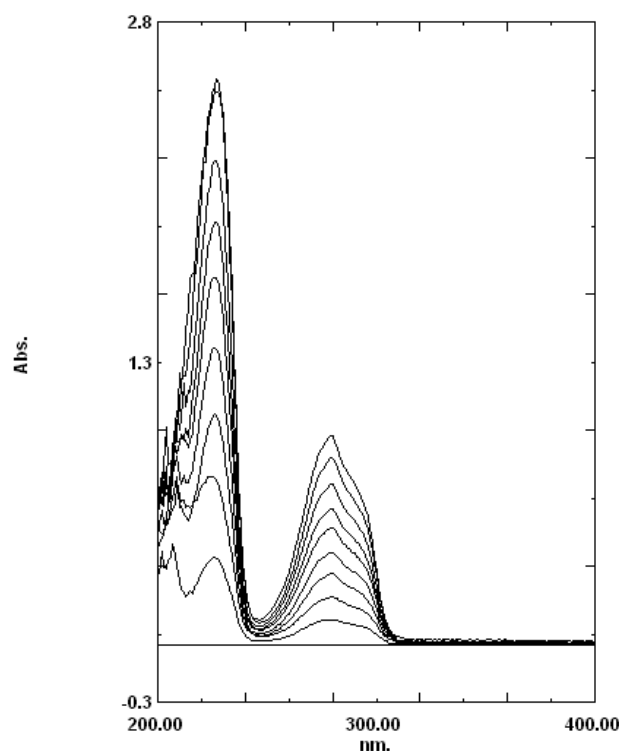

Figure 2: Zero Order UV Spectra of Tamsulosin hydrochloride in Methanol: Water (2:8) at $280 \mathrm{~nm}$.

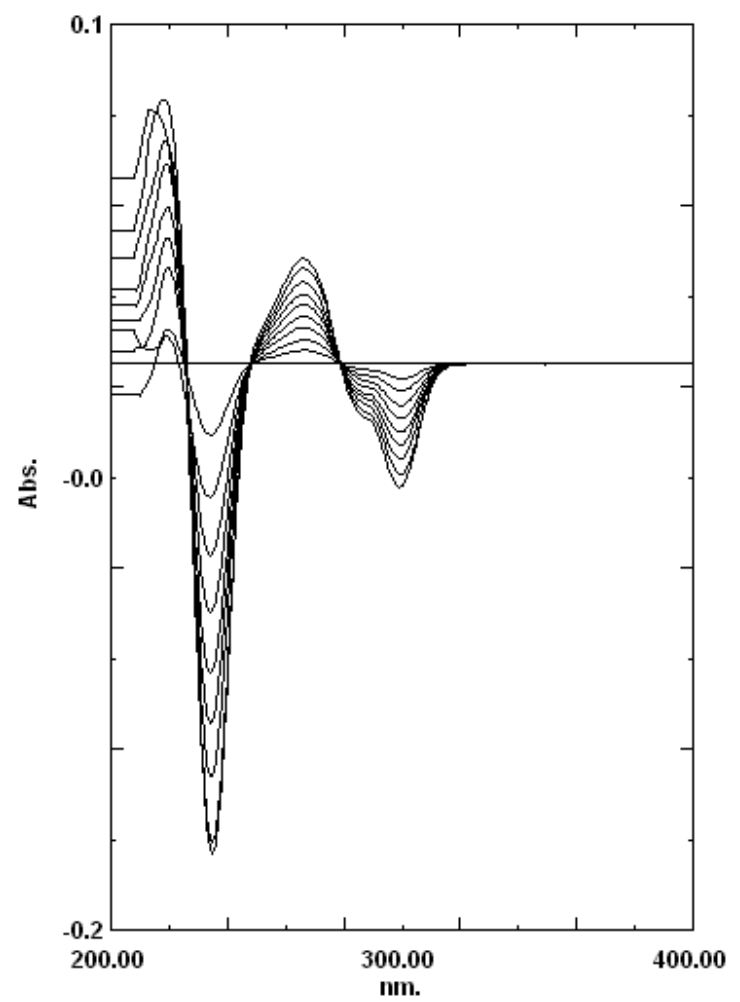

Figure 3: First Order UV Spectra of Tamsulosin hydrochloride in Methanol: Water $(2: 8)$ at $298 \mathrm{~nm}$.

derivative' the amplitude of trough was recorded at $298 \mathrm{~nm}$. In both the methods tamsulosin hydrochloride follows linearity in the concentration range $10-90 \mu \mathrm{g} / \mathrm{ml}$. Amount of drug determined was in the good agreement with the label claim. The methods were validated for accuracy, precision and ruggedness. Accuracy of the methods was assessed by recovery studies. In both the methods, as \%RSD values were found to be less than 2, indicative of accuracy of the method. Precision of the methods was studied as intra-day, inter-day and repeatability. The \%RSD values less than 2 indicate the methods are precise. Ruggedness of the proposed methods was studied with the help of two analysts, the $\%$ RSD value less than 2 indicate methods are rugged. The results from validation studies are shown in Table 1. Both these methods are simple, rapid and accurate and precise and can be used for routine analysis of tamsulosin from tablet formulations.

\section{Conclusion}

The developed method is simple, economic specific and accurate. Statistical analysis proved the method is reproducible and selective for analysis of Tamsulosin Hydrochloride as the bulk drug and in tablet formulations. The method was validated in accordance with ICH guidelines. The method can be utilized to determine the purity of the commercially available drug by detecting the related impurities.

\section{References}

1. Martindale (1989) The Extra Pharmacopoeia, Council of Royal Pharmaceutical Society of Great Britain. 29th ed. 978.

2. Budavari S (1996) The Merck Index, Merck and Co. Inc., White House station, NJ (14) 1555.

3. Maier V, Horakova J, Petr J, Tesarov E, Coufal P, et al.(2005) Chiral separation of tamsulosin by capillary electrophoresis. J Pharm Biomed Anal 39: 691-696.

4. Zhang Z, Yang G, Liang G, Liu H, Chen Y (2004) Chiral separation of Tamsulosin isomers by HPLC using cellulose Tris (3,5-dimethhylphenylcarbamate) as a chiral stationary phase. J Pharm Biomed Anal 34: 689-693.

5. Nageswara Rao R, Kumar Talluri MV, Narasa Raju A, Shinde DD Ramanjaneyulu GS (2008) Development of a validated RP-LC/ESI-MS-MS method for separation, identification and determination of related substances of tamsulosin in bulk drugs and formulations. J Pharm Biomed Anal 46: 94-103.

6. Meiling Qi, Peng Wang, Ruihua Cong (2004) Determination of the Enantiomers of Tamsulosin Hydrochloride and its Synthetic Intermediates by Chiral Liquid Chromatography. Chromatographia 59: 251-254.

7. Chandorkar JG, Kotwal VB, Dhande NS, Gurav SG, Pande VV, et al. (2008) A sensitive HPLC method for simultaneous estimation of tamsulosin hydrochloride and its impurity. Pak J Pharm Sci 21: 307-310.

8. Ding L, Li L, Ta P, Yang J, Zhang Z (2002) Quantitation of tamsulosin in human plasma by liquid chromatography-electrospray ionization mass spectrometry. $J$ Chromatogr B Analyt Technol Biomed Life Sci 767: 75-81.

9. Yamada S, Tanaka C, Suzuki M, Ohkura T, Kimura R, et al. (1996) Determination of I-adrenoceptor antagonists in plasma by radioreceptor assay. Journal of Pharmaceutical and Biomedical. Analysis, 14: 289-294.

10. Hanada K, Tochikura N, Ogata H. (2007) Selective binding of tamsulosin to genetic variants of Human alpha1-acid glycoprotein. Biol Pharm Bull 30: 15931605

11. Keski-Rahkonen P, Pärssinen O, Leppänen E, Mauriala T, Lehtonen M, et al (2007) Determination of tamsulosin in human aqueous humor and serum by liquid chromatography electrospray ionization tandem mass spectrometry. J Pharm Biomed Anal 43: 606-612. 